\title{
AVALIAÇÃO SENSORIAL DE GUEIJO PRATO OBTIDO POR MODIFICAÇÕES DO PROCESSO TRADICIONAL DE FABRICAÇÃO ${ }^{1}$
}

\author{
Leila M. SPADOTI ${ }^{2 *}$, José Raimundo F. DORNELLAS ${ }^{3}$, Salvador M. ROIG ${ }^{3}$
}

\section{RESUMO}

Os efeitos de cinco diferentes metodologias para processamento de queijo prato foram avaliados sensorialmente. Foram estudados os seguintes tratamentos (T) de elaboração de queijos: T1 - (padrão) sem o uso de leite concentrado por ultrafiltração (LCUF); T2 - com uso de LCUF sem pré-fermentação; T3 - com uso de LCUF e pré-fermentação de $10 \%$ do mesmo; T4 - com uso de LCUF e pré-fermentação de $20 \%$ do mesmo e T5 - com uso de LCUF, pré-fermentação de $20 \%$ do mesmo e o único com aquecimento indireto da massa. Segundo o teste de Análise Descritiva Quantitativa, os tratamentos diferiram significativamente entre si com relação à aparência, sabor e textura. Os queijos T3, T4 e T5 apresentaram cor amarelada mais forte e maior uniformidade na aparência e foram considerados os queijos mais duros. O queijo T1 foi considerado o mais ácido e salgado. Os queijos T4 e T5 tiveram menor derretimento. No teste de aceitação, os queijos apresentaram a seguinte ordem de preferência: T3=T4=T5>T1 $>$ T2 .

Palavras-chave: análise sensorial, queijo, ultrafiltração, fermentação.

\section{SUMMARY}

SENSORY EVALUATION OF PRATO CHEESE OBTAINED BY MODIFICATIONS OF THE TRADITIONAL MANUFACTURING PROCESS The effects of five different processing methods for prato cheese were sensorially evaluated The following treatments ( $T$ ) for cheese production were studied: T1 - (standard) without milk concentrated by ultrafiltration (LCUF); T2 - using LCUF without pre-fermentation; T3 - using LCUF and pre-fermentation of $10 \%$ of it; T4 - using LCUF and pre-fermentation of $20 \%$ of it and T5 - using LCUF, pre-fermentation of $20 \%$ of it plus indirect heating (the only one). According to the Quantitative Descriptive Analysis Test, the treatments presented significant differences among them with respect to appearance, flavor and texture. Cheeses T3, T4 and T5 presented a strongly marked yellow color, larger appearance uniformity and were considered harder. The cheese T1 was considered the most acidic and salty. The cheeses T4 and T5 presented lower melting. The cheeses presented the following order on the Acceptance Test $\mathrm{T} 3=\mathrm{T} 4=\mathrm{T} 5>\mathrm{T} 1>\mathrm{T} 2$.

Keywords: sensory evaluation, cheese, ultrafiltration, fermentation.

\section{1 - INTRODUÇÃO}

O queijo prato é um queijo de massa semicozida que começou a ser fabricado no Brasil na década de 20, por imigrantes dinamarqueses, que procuraram produzir um queijo similar aos queijos Danbo dinamarquês e Gouda holandês [5]. O processo de semicozimento da sua massa pode ser direto, pela remoção de parte do soro e adição de água quente, ou indireto, pelas paredes e fundo do tanque [17].

Ao longo dos últimos 80 anos, o queijo prato vem passando por inúmeras modificações, seja em sua tecnologia de fabricação ou na maneira como é consumido. Por ter se tornado um dos queijos mais fabricados no Brasil, foi inevitável o uso de equipamentos modernos e diferentes métodos de fabricação e maturação, o que fez com que ele se distanciasse das características típicas de textura e sabor dos queijos elaborados pelos pioneiros dinamarqueses [4].

Uma das modificações que foi estudada por RIBEIRO [14] e VAN DENDER et al. [19] na tecnologia de fabricação do queijo prato foi o uso de leite concentrado por ultrafiltração. Segundo JAMESON [8]; JENSEN \& STAPELFELDT

\footnotetext{
${ }^{1}$ Recebido para publicação em 03/08/2004. Aceito para publicação em 30/09/2005 (001385).

${ }^{2}$ Centro de Pesquisa e Desenvolvimento de Laticínios - Instituto de Tecnologia de Alimentos. Avenida Brasil, 2880 - Caixa Postal 139, CEP: 13070-178, Campinas, SP, Brasil. E-mail:lspadoti@ital.sp.gov.br

${ }^{3}$ Departamento de Tecnologia de Alimentos - Faculdade de Engenharia de Alimentos - UNICAMP. Caixa Postal 6121, CEP: 13083-970, Campinas, SP, Brasil.

*A quem a correspondência deve ser enviada.
}

[9], HICKEY [6], RENNER \& EL-SALAM [15] e ZOON [20], o uso da ultrafiltração pode apresentar inúmeras vantagens como: redução de gastos com transporte de leite, redução no tempo de fabricação dos queijos, diminuição do consumo de água, aumento da produtividade da planta e principalmente aumento no rendimento da fabricação dos queijos.

VAN DENDER et al. [19] pesquisaram o desenvolvimento de uma tecnologia de fabricação de queijo tipo prato pelo processo de concentração do leite por ultrafiltração até obtenção de um pré-queijo líquido de composição similar ao queijo tradicional, visando principalmente aumentar o rendimento de produção. Os resultados obtidos mostraram a possibilidade de se obter, além do aumento de rendimento, um queijo próximo ao queijo tipo prato do ponto de vista de composição físico-química.

Apesar das vantagens apresentadas pelo uso da técnica de ultrafiltração do leite na fabricação de queijos, vários pesquisadores (JAMESON [8], PAHKALA et al. [13] e ZOON [20]) observaram que a textura e o sabor dos queijos elaborados a partir de leite concentrado por ultrafiltração (LCUF) eram diferentes e usualmente desfavoráveis em relação ao queijo tradicional. Assim, para se obter queijos com características sensoriais similares a de um queijo tradicional, novas modificações no processo de fabricação dos queijos começaram a ser pesquisadas.

RIBEIRO [14], trabalhando com queijos tipo prato fabricados a partir de LCUF com um fator de concentração 
(FC) de 5:1 e o uso de diafiltração e pré-fermentação de uma parte (10\%) deste LCUF, concluiu ser possível a obtenção de queijos com características de textura, sabor e aparência semelhantes às de um queijo prato tradicional.

O objetivo deste trabalho foi estudar o efeito das seguintes modificações no processo tradicional de fabricação de queijo prato: uso de leite concentrado por ultrafiltração até um FC de 4:1; pré-fermentação de parte (0, 10 e 20\%) deste LCUF e variação no tipo de cozimento da massa (direto ou indireto) na avaliação sensorial dos queijos, comparando os resultados com os de um queijo padrão.

\section{2 - MATERIAL E MÉTODOS}

\section{1 - Ultrafiltração do leite}

Leite cru tipo B (250 kg), proveniente da Cooperativa dos Produtores de Leite da Região de Campinas, foi tratado termicamente a $68^{\circ} \mathrm{C} / 2 \mathrm{~min}$. Uma parte do leite (50 kg) foi resfriada a $35^{\circ} \mathrm{C}$ e transferida para cuba de fabricação de queijos para elaboração de um lote de queijo prato padrão (T1) e a outra parte $(200 \mathrm{~kg})$ foi resfriada a $55^{\circ} \mathrm{C}$ e submetida a um processo de concentração por ultrafiltração (UF). O leite foi concentrado em um sistema de UF dotado de membranas minerais com peso molecular de corte de 20.000 Daltons, TECH-SP, modelo S37, com pressão de entrada e de saída de 2,5 e 1,5 kgf/ $\mathrm{cm}^{2}$, respectivamente, até $\mathrm{FC}=4: 1$. Após o processo de concentração, o leite ultrafiltrado obtido foi pasteurizado a $63^{\circ} \mathrm{C}$ por $30 \mathrm{~min}$, resfriado a $7^{\circ} \mathrm{C}$ e dividido em quatro porções iguais, sendo cada uma delas transferida para cubas de fabricação de queijos (T2, T3, T4 e T5).

\section{2 - Fabricação dos queijos}

Neste experimento foram fabricados cinco lotes de queijos tipo prato (T1, T2, T3, T4 e T5). O lote T1 foi elaborado pelo método convencional, a partir de leite não concentrado, no mesmo dia de chegada do leite na planta piloto, e os outros quatro lotes foram elaborados a partir de LCUF no dia subseqüente. No caso dos queijos elaborados a partir de LCUF (T2, T3, T4 e T5), após o resfriamento de cada uma das quatro porções, retirou-se uma porcentagem das mesmas (0\% de T2; $10 \%$ de T3 e $20 \%$ de T4 e T5) a qual foi submetida a uma pré-fermentação a $32^{\circ} \mathrm{C}$ com cultura lática mesófila (G3 MIX 6-VISBYVAC ${ }^{\circledR}$-B50) composta por múltiplas cepas mistas de Lactococcus lactis ssp. lactis e Lactococcus lactis ssp. cremoris. O restante do LCUF foi armazenado a $5 \pm 1^{\circ} \mathrm{C}$ até o dia seguinte. As porções separadas de LCUF foram misturadas aos respectivos LCUFs após terem atingido $\mathrm{pH}$ igual a 5,0, procedendo-se então ao aquecimento dos retentados até $35^{\circ} \mathrm{C}$ para dar início ao processamento dos queijos. Tanto o queijo padrão como os ultrafiltrados foram fabricados seguindo as etapas básicas do processamento tradicional de queijo prato. No queijo padrão (T1), o leite aquecido a $35^{\circ} \mathrm{C}$ recebeu a adição de cloreto de cálcio $50 \%(0,4 \mathrm{~mL} / \mathrm{kg}$ de leite), fermento liofilizado concentrado de utilização direta no tanque, na quantidade de $10 \%$ da recomendada pelo fa- bricante, corante de urucum (Bixa orellana) e coalho (coalho de vitelo - Bela Vista - 90\% de quimosina), em quantidade suficiente para coagular o leite em 40 min. à temperatura de $35^{\circ} \mathrm{C}$. Na fabricação dos queijos a partir de LCUF procedeuse de maneira similar, utilizando-se cultura lática, corante e agente coagulante numa quantidade equivalente à que seria utilizada convertendo o LCUF em leite, porém sem o uso de cloreto de cálcio. Após a coagulação (40 minutos para todos os tratamentos), a massa foi cortada em cubos de $0,4 \mathrm{~cm} \mathrm{X}$ $0,5 \mathrm{~cm}$ de aresta, com o auxílio de liras manuais, e deixada em repouso por cinco min. Iniciou-se, então, uma agitação lenta e contínua dessa massa por cerca de 20 minutos, seguida pela remoção de parte do soro e aquecimento da coalhada sob agitação, com adição de água quente $\left(80^{\circ} \mathrm{C}\right)$ até $41^{\circ} \mathrm{C}$, de modo a se obter o ponto de massa do queijo prato. No caso dos queijos obtidos a partir de LCUF, não foi realizada a primeira fase de agitação, nem a remoção de parte do soro, assim, logo após o repouso foi realizado o aquecimento da massa, o que resultou numa redução de cerca de 30 minutos no tempo de processamento. Para os queijos dos tratamentos T2, T3 e T4 adotou-se o aquecimento direto da massa por adição de água quente $\left(80^{\circ} \mathrm{C}\right)$, sendo que para o queijo T5, adotou-se o aquecimento indireto. Após o término do semicozimento, as massas foram pré-prensadas em dreno-prensa por 20 minutos, com o dobro do peso da massa, e depois colocadas em formas plásticas de queijo prato de 0,5 kg e prensadas por seis horas em prensa vertical, com pesos de aço inox. Os queijos foram virados após 20 minutos de prensagem e a cada hora subseqüente até o momento de sair da prensa. Os pesos de prensagem foram aumentados gradativamente de 10 até 20 vezes o peso da massa. Atingido o tempo de prensagem, os queijos foram armazenados a $7 \pm 1^{\circ} \mathrm{C}$, para no dia seguinte serem colocados em salmoura ( $20 \% \mathrm{sal})$ por um período de 8 horas a $4 \pm 1^{\circ} \mathrm{C}$. Por fim foram secos a $7 \pm 1^{\circ} \mathrm{C}$, pesados, embalados a vácuo em sacos plásticos termoencolhíveis e estocados a $7 \pm 1^{\circ} \mathrm{C}$ por um período de até 45 dias.

\section{3 - Análises de composição dos queijos}

Na determinação do teor de extrato seco total (EST) foi empregada a metodologia AOAC 925.23 [1]. O teor de umidade foi determinado subtraindo-se a porcentagem de EST do valor 100. O teor de gordura foi determinado pelo método de Gerber [2]. O teor de nitrogênio total (NT) foi obtido pelo método de Kjeldahl AOAC 920.123 [1], usando o fator de conversão 6,38 para o cálculo de proteína total. Os valores de $\mathrm{pH}$ foram determinados pelo método potenciométrico, e os de acidez titulável (AT) e de sal (\%) foram obtidos a partir da metodologia AOAC 920.124 [1] e pelo método de Volhard [16], respectivamente. Todas as determinações foram feitas em triplicata, nos queijos com 10 dias de armazenamento refrigerado.

\section{4 - Análise Descritiva Quantitativa}

O perfil de cada amostra foi avaliado pelo método de Análise Descritiva Quantitativa (ADQ), adaptado a partir da metodologia descrita em STONE et al. [18]. A aplicação da ADQ envolveu quatro etapas. 
Na primeira etapa, a de seleção da equipe de provadores, 35 consumidores de queijo prato, da Faculdade de Engenharia de Alimentos da UNICAMP, foram submetidos a três testes triangulares, realizados utilizando-se três marcas de queijo prato disponíveis no mercado. Doze provadores, que demonstraram habilidade para discriminar as amostras em $100 \%$ dos testes, foram selecionados para participarem da etapa de desenvolvimento de terminologia descritiva das amostras de queijo prato.

Nesta segunda etapa da ADQ, sob a supervisão de um líder, foram definidos os termos verbais (descritores) que descreveriam as características de aparência, sabor e textura a serem avaliadas no queijo prato (Tabela 1 ). Iniciou-se então a terceira etapa, de treinamento e seleção final dos provadores.

Durante o treinamento, os provadores foram solicitados a avaliar a intensidade de cada descritor sensorial previamente gerado, em várias amostras de queijo prato. Para cada avaliação, os provadores utilizaram uma ficha de avaliação contendo os termos descritivos e uma escala linear não estruturada de $9 \mathrm{~cm}$, ancorada à esquerda e à direita, com termos pouco (ou nenhum ou fraco ou curta) e muito (ou forte ou longa), respectivamente. Tanto a lista de definições dos termos descritivos (Tabela 1) como os materiais de referência, foram rotineiramente revistos pelos provadores em cada sessão de treinamento, antes da avaliação das amostras. Os resultados individuais destas avaliações foram discutidos pelo grupo, sob a supervisão do líder da equipe, com o objetivo de se otimizar o processo de avaliação.
A aparência dos queijos foi avaliada com relação aos atributos: cor amarelada, uniformidade da cor da massa e derretimento. Para os dois primeiros atributos foram utilizadas fatias de queijo de $2 \mathrm{~cm} \times 2 \mathrm{~cm} \times 0,5 \mathrm{~cm}$, à temperatura de refrigeração, servidas em pratos plásticos de cor branca codificados com números de três dígitos em etiqueta branca de papel. O derretimento foi avaliado submetendo-se fatias de queijo de $2 \mathrm{~cm} \times 2 \mathrm{~cm} \times 0,5 \mathrm{~cm}$ colocadas sobre biscoito água e sal, à temperatura de $250^{\circ} \mathrm{C}$ por 20 segundos. A avaliação da aparência foi conduzida em cabines individuais, sob luz branca.

O sabor dos queijos foi avaliado com relação aos atributos gosto ácido, gosto salgado e gosto amargo. Para avaliação destes atributos, foram servidas amostras de $2 \mathrm{~cm} \mathrm{x} 2 \mathrm{~cm} \mathrm{x}$ $0,5 \mathrm{~cm}$, monadicamente, à temperatura de refrigeração.

A textura foi avaliada com relação aos atributos dureza e coesividade a partir de metodologias táteis. Para o teste de dureza, cada provador recebeu uma amostra cilíndrica ( $2 \mathrm{~cm}$ de altura x $2 \mathrm{~cm}$ de diâmetro) de queijo, à temperatura de refrigeração, de cada tratamento, para ser pressionada com o dedo indicador. Os provadores também receberam amostras de queijo de $15 \mathrm{~cm}$ de comprimento $\mathrm{x} 0,5 \mathrm{~cm}$ de largura x 0,5 cm de altura, que foram submetidas ao teste de união das extremidades a fim de verificar a coesividade da amostra de cada tratamento.

Após o período de treinamento, foi realizada uma seleção final dos provadores com base no poder discriminativo dos indivíduos, na reprodutibilidade dos resultados apresentados por eles e na concordância

TABELA 1 - Definição dos descritores e referências de extremos de escala adotados na análise descritiva quantitativa

\begin{tabular}{|c|c|c|}
\hline Atributos Sensoriais & Definição & Referências de extremos de escala \\
\hline $\begin{array}{l}\text { Aparência } \\
1 \text { - Cor amarela }\end{array}$ & $\begin{array}{l}\text { Sensação produzida pela estimulação da retina pelos raios } \\
\text { luminosos do comprimento e onda da cor amarela }\end{array}$ & $\begin{array}{l}\text { Fraca }=\text { queijo prato maturado por um ano } \\
\text { Forte }=\text { queijo do Reino }\end{array}$ \\
\hline 2 - Uniforme & $\begin{array}{l}\text { Propriedade visível de uma substância, que se refere à distribuição } \\
\text { de cor, forma e característica de superfície. }\end{array}$ & $\begin{array}{l}\text { Pouco = queijo com muitas manchas } \\
\text { Muito = queijo sem presença de manchas }\end{array}$ \\
\hline 3 - Derretimento & $\begin{array}{l}\text { Capacidade de fusão do alimento quando submetido à temperatura } \\
\text { de } 250^{\circ} \mathrm{C} \text { por } 20 \mathrm{seg} \text { em forno elétrico sobre biscoito água e sal. }\end{array}$ & $\begin{array}{l}\text { Pouco }=\text { nenhuma alteração } \\
\text { Muito = Fatia de } 2 \mathrm{~cm} \times 2 \mathrm{~cm} \times 0,5 \mathrm{~cm} \text { derrete } \\
\text { ao longo da superfície do biscoito }\end{array}$ \\
\hline $\begin{array}{l}\text { Sabor } \\
4-\text { Ácido }\end{array}$ & $\begin{array}{l}\text { Descreve o gosto primário produzido por soluções aquosas de } \\
\text { substâncias ácidas, semelhante à solução de ácido lático. }\end{array}$ & $\begin{array}{l}\text { Nenhum = água destilada } \\
\text { Forte }=\text { iogurte natural }\end{array}$ \\
\hline 5 - Salgado & $\begin{array}{l}\text { Descreve o gosto primário produzido por soluções aquosas de } \\
\text { substâncias salgadas, semelhante à solução de cloreto de sódio. }\end{array}$ & $\begin{array}{l}\text { Fraco }=0,4 \mathrm{~g} \text { de } \mathrm{NaCl} \text { em } 500 \mathrm{ml} \text { de água destilada } \\
\text { Forte }=3 \mathrm{~g} \text { de } \mathrm{NaCl} \text { em } 500 \mathrm{ml} \text { de água destilada }\end{array}$ \\
\hline 6 - Amargo & $\begin{array}{c}\text { Descreve o gosto primário produzido por soluções aquosas de } \\
\text { substâncias amargas, semelhante a soluções de sais de quinino e } \\
\text { cafeína. }\end{array}$ & $\begin{array}{l}\text { Fraco = queijo prato novo } \\
\text { Forte = queijo prato amargo }\end{array}$ \\
\hline \multicolumn{3}{|c|}{ 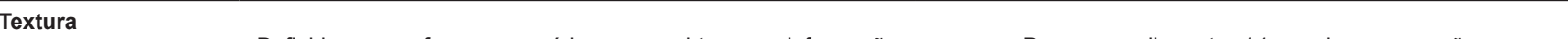 } \\
\hline 7 - Dureza & $\begin{array}{l}\text { Definida como a força necessária para se obter uma deformação } \\
\text { em um cilindro de } 2 \mathrm{~cm} \times 2 \mathrm{~cm} \text { diâmetro }\end{array}$ & $\begin{array}{l}\text { Pouca = queijo prato c/ } 1 \text { ano de conservação } \\
\text { Muita =queijo parmesão }\end{array}$ \\
\hline 8 - Coesividade & $\begin{array}{l}\text { Forças das ligações internas que dão resistência à quebra, a uma } \\
\text { fatia de } 15 \mathrm{~cm} \times 0,5 \times 0,5 .\end{array}$ & $\begin{array}{c}\text { Curta }=\text { ao unir extremidades, a fatia se rompe ao } 1^{\circ} \text { movimento } \\
\text { Longa }=\text { ao unir as extremidades, a fatia não se rompe }\end{array}$ \\
\hline
\end{tabular}


destes resultados com os demais membros da equipe, para compor a equipe descritiva treinada de queijo prato. Com este objetivo, três amostras de queijo prato de diferentes marcas comerciais, representativas da variabilidade sensorial existente no mercado, foram avaliadas por cada indivíduo, em três repetições. Uma análise de variância univariada (ANOVA) foi calculada para cada provador, em cada atributo julgado, e o nível de significância ( $p$ ) para os valores $\mathrm{F}_{\text {amostra }}$ e $\mathrm{F}_{\text {repetiçăo }}$ foram computados. Indivíduos mostrando valores de $\mathrm{p}_{\text {amostra, }}$, $\mathrm{p}_{\text {repeticăó }}$ médias e desvios padrões inconsistentes com a equipe sensorial não foram recrutados. Dos 12 provadores submetidos ao treinamento e seleção final, 11 passaram para a quarta etapa da ADQ que correspondeu ao teste sensorial envolvendo a avaliação das amostras de queijos dos cinco tratamentos estudados neste experimento. Os queijos foram avaliados com 45 dias de estocagem, nos mesmos moldes utilizados anteriormente para queijos de marcas comerciais (Tabela 1 ).

\section{5 - Teste de Aceitação}

Para os testes de aceitação dos queijos deste experimento, foi utilizada uma escala hedônica estruturada de 9 pontos para os atributos aparência, cor, sabor e textura. Para avaliar a intenção de compra foi adotada uma escala hedônica estruturada de cinco pontos. Os queijos foram avaliados com 10 (D10), 25 (D25) e 45 (D45) dias de estocagem. Foi utilizado o modelo experimental de blocos completos casualizados, aplicados a sessenta e cinco provadores não treinados. Os testes foram realizados em cabines individuais, sob luz branca. As amostras de $3 \mathrm{~cm} \times 3 \mathrm{~cm} \times 0,5 \mathrm{~cm}$ foram servidas em pratos plásticos codificados à temperatura de refrigeração. Cada provador recebeu as amostras monadicamente e marcou suas apreciações e comentários em ficha única.

\section{6 - Análise estatística}

$\mathrm{Na}$ avaliação sensorial pelo método $\mathrm{ADQ}$ os queijos dos cinco tratamentos foram avaliados com 45 dias de estocagem, em três repetições. No teste de aceitação os queijos foram avaliados uma única vez com 10, 25 e 45 dias de estocagem. Os resultados da $\mathrm{ADQ}$ e do teste de aceitação foram analisados por Análise de Variância (ANOVA) e teste de Tukey ( $5 \%$ de significância) pelo programa estatístico SAS ${ }^{\circledast}$, versão 6.11 (SAS Institute, Inc., Cary, NC.).

\section{3 - RESULTADOS E DISCUSSÃO}

\section{1 - Composição dos queijos}

A composição dos queijos avaliados sensorialmente é apresentada na Tabela 2.

TABELA 2 - Composição dos queijos obtidos sem ultrafiltração (T1) e com ultrafiltração (FC 4:1): sem pré-fermentação (T2), com $10 \%$ de pré-fermentação (T3), com $20 \%$ de pré-fermentação (T4) e com $20 \%$ de pré-fermentação e único com aquecimento indireto (T5)

\begin{tabular}{|c|c|c|c|c|c|}
\hline Parâmetros avaliados & T1 & T2 & T3 & T4 & T5 \\
\hline Umidade $^{1}(\%)$ & 45,11 & 48,22 & 41,97 & 41,84 & 40,93 \\
\hline Gordura $^{1}(\%)$ & 25,30 & 24,67 & 25,67 & 25,33 & 26,00 \\
\hline Proteína Total ${ }^{1}(\%)$ & 18,02 & 20,13 & 22,13 & 21,83 & 22,72 \\
\hline Sal $^{1}(\%)$ & 1,85 & 1,76 & 1,47 & 1,29 & 1,38 \\
\hline $\begin{array}{l}\text { Acidez titulável }{ }^{1} \text { (\%de } \\
\text { ácido lático) }\end{array}$ & 0,53 & 0,65 & 0,74 & 0,97 & 0,87 \\
\hline $\begin{array}{l}\text { Acidez titulável }{ }^{2} \text { (\%de } \\
\text { ácido lático) }\end{array}$ & 0,84 & 0,86 & 0,80 & 1,07 & 0,95 \\
\hline $\mathrm{pH}^{1}$ & 5,38 & 5,34 & 5,24 & 5,12 & 5,19 \\
\hline $\mathrm{pH}^{2}$ & 5,72 & 5,27 & 5,38 & 5,20 & 5,31 \\
\hline
\end{tabular}

Os valores de composição e pH para os queijos T1, T2, T3, T4 e T5, apresentados na Tabela 2 encontram-se na média dos valores relatados por FURTADO \& LOURENÇO NETO [5] para um queijo prato, com exceção do queijo T2, que apresenta umidade levemente maior.

\section{2 - Análise Descritiva Quantitativa}

A Figura 1 mostra o perfil sensorial dos queijos analisados e a Tabela 3 os resultados da análise estatística dos dados referentes aos atributos sensoriais avaliados neste experimento.

A análise do perfil dos queijos deste experimento mostra que, com relação à aparência, os queijos avaliados tiveram o seguinte comportamento: embora os queijos T1, T2, T3, T4 e T5 terem diferido entre si, os queijos T3, T4 e T5 apresentaram cor amarelada mais forte, os queijos T4 e T5 foram os que mostraram uma coloração mais uniforme da massa e o queijo T2 foi o que apresentou uma coloração amarelada mais fraca e menos uniforme. Com relação ao derretimento, os queijos T1, T2 e T3 foram os que apresentaram maior derretimento.

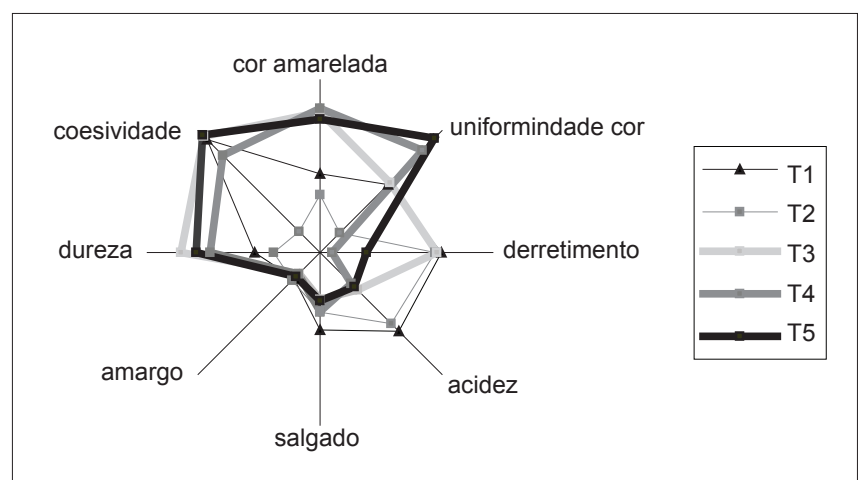

FIGURA 1 - Representação gráfica dos resultados da análise descritiva quantitativa dos queijos obtidos sem ultrafiltração (T1) e com ultrafiltração (FC 4:1): sem pré-fermentação (T2), com $10 \%$ de pré-fermentação (T3), com $20 \%$ de pré-fermentação (T4) e com $20 \%$ de pré-fermentação e único com aquecimento indireto (T5) 
TABELA 3 - Pontuação média recebida, na Análise Descritiva Quantitativa, para as propriedades sensoriais aparência, gosto e textura, pelos queijos obtidos sem ultrafiltração (T1) e com ultrafiltração (FC 4:1): sem pré-fermentação (T2), com $10 \%$ de pré-fermentação (T3), com $20 \%$ de pré-fermentação (T4) e com $20 \%$ de pré-fermentação e único com aquecimento indireto (T5)

\begin{tabular}{lccccc}
\hline & T1 & T2 & T3 & T4 & T5 \\
\hline Aparência & & & & & \\
Cor amarelada & $4,11^{\mathrm{d}}$ & $3,02^{\mathrm{e}}$ & $7,32^{\mathrm{b}}$ & $7,52^{\mathrm{a}}$ & $6,96^{\mathrm{c}}$ \\
Uniformidade da cor & $4,98^{\mathrm{d}}$ & $1,47^{\mathrm{e}}$ & $5,12^{\mathrm{c}}$ & $7,52^{\mathrm{b}}$ & $8,43^{\mathrm{a}}$ \\
Derretimento & $6,32^{\mathrm{a}}$ & $6,00^{\mathrm{c}}$ & $6,08^{\mathrm{b}}$ & $0,62^{\mathrm{e}}$ & $2,42^{\mathrm{d}}$ \\
\hline Gosto & & & & & \\
Ácido & $5,79^{\mathrm{a}}$ & $5,22^{\mathrm{b}}$ & $2,76^{\mathrm{c}}$ & $2,32^{\mathrm{e}}$ & $2,55^{\mathrm{d}}$ \\
Salgado & $4,03^{\mathrm{a}}$ & $3,11^{\mathrm{b}}$ & $2,46^{\mathrm{c}}$ & $3,07^{\mathrm{b}}$ & $2,50^{\mathrm{c}}$ \\
Amargo & $1,93^{\mathrm{b}}$ & $2,05^{\mathrm{a}}$ & $1,51^{\mathrm{d}}$ & $1,60^{\mathrm{d}}$ & $1,78^{\mathrm{c}}$ \\
\hline Textura & & & & & \\
Dureza & $3,42^{\mathrm{d}}$ & $2,40^{\mathrm{e}}$ & $7,25^{\mathrm{a}}$ & $5,72^{\mathrm{c}}$ & $6,46^{\mathrm{b}}$ \\
Coesividade & $8,33^{\mathrm{c}}$ & $1,54^{\mathrm{e}}$ & $8,57^{\mathrm{b}}$ & $7,15^{\mathrm{d}}$ & $8,65^{\mathrm{a}}$ \\
\hline
\end{tabular}

Obs. 1: Médias com letras iguais, na mesma linha, não diferem significativamente entre si $(\mathrm{p}>0,05)$.

Os queijos T1, T2 e T3 possivelmente apresentaram um derretimento maior do que os queijos T4 e T5 em função das relações gramas de água/gramas de proteína e dos valores de $\mathrm{pH}$ apresentados pelos mesmos $(\mathrm{T} 1=2,50$ e 5,72; T2 $=2,40$ e 5,27; T3 $=1,90$ e 5,38; T4=1,92 e 5,20; $\mathrm{T} 5=1,80$ e 5,31). MCMAHON et al. [12] observaram que uma matriz protéica mais hidratada, quando aquecida, resulta num aumento da capacidade de derretimento dos queijos. Além disso, de acordo com KINDSTEDT et al. [10], o pH afeta fortemente as interações proteína - umidade e, conseqüentemente, o derretimento do queijo, tendo estes autores observado que queijos mussarela perdiam a habilidade de derretimento a valores de $\mathrm{pH}$ menores que 5,0.

O derretimento dos queijos nos diferentes tratamentos também foi avaliado pelos autores através de um teste físico (método objetivo) e os resultados deste teste físico concordaram com os obtidos pelo teste sensorial (método subjetivo) realizado neste experimento.

Com relação ao sabor, os queijos T1 e T2 foram os que apresentaram gosto mais ácido. O queijo T1 foi o que mostrou ter gosto salgado mais forte, seguido pelos queijos T2 e T4. Os queijos T3 e T5 foram os que apresentaram gosto salgado mais fraco. Com relação ao gosto amargo, embora os queijos tenham obtido pontuações médias próximas, eles diferiram significativamente entre si $(p<0,05)$, tendo o queijo T2 apresentado a maior pontuação, possivelmente pelo fato de ter sido o queijo que apresentou o menor teor de gordura (Tabela 2). Segundo estudos realizados por MADSEN \& ARDO [11], com queijos Danbo com diferentes porcentagens de gordura, os consumidores tendem a perceber o amargor mais facilmente em queijos menos gordurosos, uma vez que a gordura mascara o amargor.

Com relação à textura, os queijos elaborados com LCUF pré-fermentado (T3, T4 e T5) foram os mais duros. O queijo fabricado com LCUF sem pré-fermentação (T2) foi o menos duro. Possivelmente os queijos T1 e $\mathrm{T} 2$ foram considerados menos duros que os queijos T3,
T4 e T5 por apresentarem maiores teores de umidade (Tabela 2). HYDAMAKA et al. [7] também verificaram que queijos com uma umidade relativamente mais alta eram considerados mais macios, segundo análise de um júri formado por 6 provadores experientes.

Os queijos T1, T3 e T5 apresentaram valores de coesividade muito próximos, sendo que o queijo T2 foi o que apresentou coesividade mais curta.

\section{3 - Teste de Aceitação}

\subsection{1 - Avaliação dos atributos Aparência e Cor}

Os queijos avaliados com 10 dias de estocagem apresentaram comportamento similar para os atributos aparência e cor, sendo que para ambos os atributos as maiores pontuações foram dadas para os queijos T4 e T5 e as menores pontuações para o queijo T2 (Tabelas 4 e 5).

TABELA 4 - Pontuação média recebida para o atributo aparência (Teste de Aceitação) pelos queijos obtidos sem ultrafiltração (T1) e com ultrafiltração (FC 4:1): sem pré-fermentação (T2), com $10 \%$ de pré-fermentação (T3), com $20 \%$ de pré-fermentação (T4) e com $20 \%$ de pré-fermentação e único com aquecimento indireto (T5)

\begin{tabular}{lccccc}
\hline Dias & T1 & T2 & T3 & T4 & T5 \\
\hline 10 & $5,08^{\mathrm{b}}$ & $3,17^{\mathrm{c}}$ & $5,03^{\mathrm{b}}$ & $6,17^{\mathrm{a}}$ & $6,00^{\mathrm{a}}$ \\
25 & $5,09^{\mathrm{c}}$ & $3,08^{\mathrm{d}}$ & $5,74^{\mathrm{bc}}$ & $6,69^{\mathrm{a}}$ & $6,21^{\mathrm{ab}}$ \\
45 & $5,28^{\mathrm{c}}$ & $3,75^{\mathrm{d}}$ & $6,17^{\mathrm{b}}$ & $6,85^{\mathrm{a}}$ & $6,63^{\mathrm{ab}}$ \\
\hline
\end{tabular}

Obs.1: Médias com letras iguais, na mesma linha, não diferem significativamente entre si $(\mathrm{p}>0,05)$

TABELA 5 - Pontuação média recebida para o atributo cor (Teste de Aceitação) pelos queijos obtidos sem ultrafiltração (T1) e com ultrafiltração (FC 4:1): sem pré-fermentação (T2), com $10 \%$ de pré-fermentação (T3), com $20 \%$ de pré-fermentação (T4) e com $20 \%$ de pré-fermentação e único com aquecimento indireto (T5)

\begin{tabular}{lccccc}
\hline Dias & T1 & T2 & T3 & T4 & T5 \\
\hline 10 & $5,52^{\mathrm{b}}$ & $3,37^{\mathrm{c}}$ & $5,38^{\mathrm{b}}$ & $6,66^{\mathrm{a}}$ & $6,34^{\mathrm{a}}$ \\
25 & $5,29^{\mathrm{c}}$ & $3,32^{\mathrm{d}}$ & $6,22^{\mathrm{b}}$ & $7,02^{\mathrm{a}}$ & $6,63^{\mathrm{ab}}$ \\
45 & $5,45^{\mathrm{b}}$ & $4,14^{\mathrm{c}}$ & $6,54^{\mathrm{a}}$ & $6,95^{\mathrm{a}}$ & $6,92^{\mathrm{a}}$ \\
\hline
\end{tabular}

Obs.1: Médias com letras iguais, na mesma linha, não diferem significativamente entre si $(\mathrm{p}>0,05)$

Segundo a avaliação dos provadores, o queijo T2 recebeu as menores pontuações para os atributos aparência e cor por apresentar manchas e pontos avermelhados (concentração de corante), o que conferiu ao produto uma aparência não-uniforme. Além disso, a cor amarelada da massa foi considerada muito clara para um queijo tipo prato.

Com relação ao queijo T3, os provadores também notaram a presença de manchas e pontos avermelhados e de uma aparência não-uniforme, porém em uma intensidade menor do que a observada no queijo T2. No queijo padrão, a crítica foi com relação à coloração amarelada (considerada um pouco mais clara que o ideal) e com relação à presença na amostra de duas regiões com características 
de cor distintas: uma região periférica mais clara e uma região interna mais amarelada.

Segundo FURTADO [3], este defeito no queijo prato padrão é denominado de bicoloração e surge nas primeiras semanas de estocagem, tendendo a desaparecer ao longo da maturação, tendo como uma das possíveis causas um $\mathrm{pH}$ não suficientemente baixo no momento da salga $(5,1 \mathrm{a}$ 5,2 para queijos de massa semicozida). Considerando-se que o queijo padrão apresentava um valor superior a 5,2, possivelmente esta foi a causa da bicoloração. O queijo T2, embora também apresentasse $\mathrm{pH}$ maior que 5,2, era mais úmido, e de acordo com FURTADO [3], em queijos mais úmidos esse defeito é minimizado.

De modo geral, os queijos T4 e T5 foram considerados os mais uniformes e com uma coloração mais adequada, o que conferiu aos mesmos maiores pontuações para os atributos aparência e cor.

Observou-se que, durante a estocagem, os valores das pontuações, com raras exceções, tenderam a aumentar (Tabelas 4 e 5), indicando uma melhora na apreciação da cor e da aparência do produto. Porém, os queijos T4 e T5 continuaram a ter as maiores pontuações para os atributos cor e aparência e o queijo T2 as menores (Tabela 4 e 5), em função de manter sua falta de uniformidade e coloração mais clara que a ideal para queijo prato. As opiniões dos provadores com relação à coloração e uniformidade dos queijos estão de acordo com a avaliação feita pelo painel treinado para a ADQ (Tabela 3).

\subsection{2 - Avaliação do atributo Sabor}

Com 10 dias de estocagem, apenas o queijo T2 diferiu dos demais, com relação ao sabor (Tabela 6). Porém, para todos os tratamentos, houve uma parcela de provadores que julgou os queijos um pouco ácidos e amargos. Os queijos T3 e T5 foram considerados com pouco sal, fato este também observado na ADQ (Tabela 3).

Com 25 dias de estocagem, o queijo T4 passou a não diferir significativamente do queijo T2. Segundo a avaliação de $30 \%$ dos provadores, o queijo T4 foi considerado levemente amargo, o que prejudicou o seu sabor.

Os queijos T1, T3, T4 e T5 continuaram a não diferir significativamente entre si com 45 dias de estocagem, porém, com exceção do queijo T3, os demais apresentaram uma redução de pontuação (Tabela 6). O queijo T2 apesar de ter apresentado melhora no sabor continuou tendo a menor pontuação para este atributo.

Com 45 dias de estocagem, a queda na apreciação dos consumidores dos queijos T4 e T5 também foi motivada pela presença de um leve amargor, o que fez com que os mesmos não diferissem significativamente de T2. Embora os queijos T4 e T5 não tenham diferido significativamente de T1 e T3, com 45 dias de estocagem, os queijos T1 e T3 foram citados como os de melhor sabor por um número maior de provadores.

TABELA 6 - Pontuação média recebida para o atributo sabor (Teste de Aceitação) pelos queijos obtidos sem ultrafiltração (T1) e com ultrafiltração (FC 4:1): sem pré-fermentação (T2), com $10 \%$ de pré-fermentação (T3), com $20 \%$ de pré-fermentação (T4) e com $20 \%$ de pré-fermentação e único com aquecimento indireto (T5)

\begin{tabular}{lccccc}
\hline Dias & T1 & T2 & T3 & T4 & T5 \\
\hline 10 & $6,40^{\mathrm{a}}$ & $4,80^{\mathrm{b}}$ & $6,29^{\mathrm{a}}$ & $6,29^{\mathrm{a}}$ & $6,72^{\mathrm{a}}$ \\
25 & $6,28^{\mathrm{a}}$ & $4,85^{\mathrm{b}}$ & $6,05^{\mathrm{a}}$ & $5,55^{\mathrm{ab}}$ & $6,20^{\mathrm{a}}$ \\
45 & $6,22^{\mathrm{a}}$ & $5,26^{\mathrm{b}}$ & $6,29^{\mathrm{a}}$ & $5,58^{\mathrm{ab}}$ & $5,78^{\mathrm{ab}}$ \\
\hline
\end{tabular}

Obs.1: Médias com letras iguais, na mesma linha, não diferem significativamente entre si $(\mathrm{p}>0,05)$

As informações obtidas através do teste de aceitação para os queijos com 45 dias de estocagem diferem das obtidas na ADQ com relação ao sabor amargo nos queijos. De acordo com o teste de aceitação: 0\% (T1); 7,7\% (T2); 15,4\% (T3); $26,2 \%$ (T4) e $23,1 \%$ (T5) dos provadores identificaram um leve amargor nas amostras de queijos, sendo que na ADQ (Tabela 3), as amostras T5, T4 e T3 foram as que tiveram menor pontuação para gosto amargo.

\subsection{3 - Avaliação do atributo Textura}

Os queijos dos tratamentos que utilizaram LCUF préfermentado (T3, T4 e T5) foram os que receberam maiores pontuações para textura com 10 dias de estocagem, não diferindo significativamente entre si ( $p>0,05)$ (Tabela 7). O queijo elaborado com LCUF sem pré-fermentação (T2) foi o mais criticado pelos provadores com relação à textura.

TABELA 7 - Pontuação média recebida para o atributo textura (Teste de Aceitação) pelos queijos obtidos sem ultrafiltração (T1) e com ultrafiltração (FC 4:1): sem pré-fermentação (T2), com $10 \%$ de pré-fermentação (T3), com $20 \%$ de pré-fermentação (T4) e com $20 \%$ de pré-fermentação e único com aquecimento indireto (T5).

\begin{tabular}{lccccc}
\hline Dias & T1 & T2 & T3 & T4 & T5 \\
\hline 10 & $5,83^{\mathrm{b}}$ & $4,54^{\mathrm{c}}$ & $6,69^{\mathrm{a}}$ & $6,61^{\mathrm{a}}$ & $6,71^{\mathrm{a}}$ \\
25 & $5,91^{\mathrm{b}}$ & $4,46^{\mathrm{c}}$ & $6,83^{\mathrm{a}}$ & $6,29^{\mathrm{ab}}$ & $6,75^{\mathrm{a}}$ \\
45 & $4,94^{\mathrm{b}}$ & $4,83^{\mathrm{c}}$ & $7,15^{\mathrm{a}}$ & $6,26^{\mathrm{ab}}$ & $6,82^{\mathrm{a}}$ \\
\hline
\end{tabular}

Obs.1: Médias com letras iguais, na mesma linha, não diferem significativamente entre si $(\mathrm{p}>0,05)$.

O queijo T1 recebeu pontuações menores que os queijos T3, T4 e T5 por apresentar o defeito da bicoloração. Este defeito além de resultar em queijos com duas camadas de coloração distintas, como relatado anteriormente, também gera duas camadas com características de textura diferenciadas, sendo a região periférica (mais clara) mais borrachenta e a região central (mais amarelada) mais mole.

Durante a estocagem (45 dias), os queijos T3, T4 e T5 continuaram a ser os preferidos em termos de textura e o queijo T2 o menos apreciado (Tabela 7). Considerando os resultados da ADQ (Tabela 3), a textura do queijo T2 possivelmente foi menos apreciada em função de sua baixa dureza.

\section{Avaliação da Intenção de Compra}

Os queijos T5 e T4 foram os que apresentaram, com 10 dias de estocagem, maiores intenções de compra, seguidos pelos queijos T3 e T1 (Tabela 8). Os queijos T1, T2 e T3 
receberam pontuações menores, segundo os provadores, por apresentarem aparência e coloração pouco atrativas.

Com 25 dias de estocagem, embora os queijos T4 e T5 continuassem entre os queijos com maiores possibilidades de compra, receberam pontuações inferiores às recebidas com 10 dias de estocagem (Tabela 8). A possível causa foi o aumento no número de provadores que passaram a detectar um leve amargor nestes queijos. O queijo T3 aumentou sua intenção de compra e, com base nas observações dos provadores, esse fato ocorreu principalmente em função de uma melhoria na sua textura. Os queijos T1 e T2 mantiveram menores intenções de compra em função de sua coloração, aparência e textura.

TABELA 8 - Pontuação média recebida para intenção de compra (Teste de Aceitação) pelos queijos obtidos sem ultrafiltração (T1) e com ultrafiltração (FC 4:1): sem pré-fermentação (T2), com $10 \%$ de pré-fermentação (T3), com $20 \%$ de pré-fermentação (T4) e com $20 \%$ de pré-fermentação e único com aquecimento indireto (T5)

\begin{tabular}{lccccc}
\hline Dias & T1 & T2 & T3 & T4 & T5 \\
\hline 10 & $3,23^{\mathrm{b}}$ & $1,98^{\mathrm{c}}$ & $3,23^{\mathrm{b}}$ & $3,48^{\mathrm{ab}}$ & $3,77^{\mathrm{a}}$ \\
25 & $2,92^{\mathrm{b}}$ & $1,85^{\mathrm{c}}$ & $3,35^{\mathrm{ab}}$ & $3,32^{\mathrm{ab}}$ & $3,48^{\mathrm{a}}$ \\
45 & $3,03^{\mathrm{a}}$ & $2,32^{\mathrm{b}}$ & $3,41^{\mathrm{a}}$ & $3,35^{\mathrm{ab}}$ & $3,38^{\mathrm{a}}$ \\
\hline
\end{tabular}

Obs.1: Médias com letras iguais, na mesma linha, não diferem significativamente entre si $(\mathrm{p}>0,05)$

Com 45 dias de estocagem o queijo T1 apresentou um pequeno aumento na sua intenção de compra. O queijo T2 também apresentou um aumento na sua intenção de compra continuando, no entanto, com uma pontuação inferior ao ponto médio da escala de intenção de compra possivelmente por continuar a apresentar características de sabor, cor e textura não-atrativas.

\section{4 - CONCLUSÕES}

De acordo com os resultados da Análise Descritiva Quantitativa, o uso de LCUF, de pré-fermentação de parte deste LCUF e de dois tipos de cozimento da massa afetaram a aparência, o gosto e a textura dos queijos prato fabricados.

Os queijos elaborados a partir de LCUF pré-fermentado ( 10 e $20 \%$ ) apresentaram cor amarelada mais forte e maior uniformidade na aparência.

A avaliação do derretimento por parte do painel sensorial caracterizou os queijos elaborados com LCUF préfermentado (20\%) como tendo pouco derretimento.

O queijo padrão foi considerado mais ácido e mais salgado que os queijos dos demais tratamentos e apresentou gosto amargo mais fraco que o queijo elaborado com LCUF sem pré-fermentação e mais forte que os queijos elaborados com LCUF pré-fermentado.

Os queijos elaborados com LCUF pré-fermentado foram considerados mais duros que o padrão, que por sua vez também foi mais duro que o queijo elaborado com LCUF sem pré-fermentação.
Segundo os resultados do Teste de Aceitação, o queijo elaborado a partir de LCUF sem pré-fermentação foi o único que possivelmente não seria comprado por apresentar baixas pontuações para os atributos aparência, cor e textura em todas as datas de avaliação. Os queijos T4 e T5 foram considerados como os de melhor aparência e cor. Os queijos T1, T3, T4 e T5 não diferiram significativamente entre si com relação ao sabor, porém os queijos T1 e T3 foram considerados os mais saborosos pelos provadores, no final do período de estocagem, por não apresentarem (T1) ou apresentarem (T3) um gosto amargo fraco. Com relação à textura, os queijos elaborados a partir de LCUF pré-fermentado receberam as maiores pontuações.

\section{5 - REFERÊNCIAS BIBLIOGRÁFICAS}

[1] AOAC-ASSOCIATION OF ANALYTICAL CHEMISTS. Official Methods of Analysis of AOAC International. Washington: AOAC, 1995.

[2] BRITISH STANDARDS INSTITUTION. Determination of Fat Content of Milk and Milk Products (Gerber Method). Methods. London: British Standards Institution, 1989.

[3] FURTADO, M.M. A Arte e a Ciência do Queijo. São Paulo: Globo, 1991.

[4] FURTADO, M.M.; AMORIM, A.C.B. Os pioneiros laticinistas dinamarqueses e a história do queijo prato. Indústria de Laticínios, n. 4, p. 18-22, 2000.

[5] FURTADO, M.M.; LOURENÇO NETO, J.P.M. Tecnologia de Queijos: Manual Técnico para a Produção Industrial de Queijos. São Paulo: Dipemar Ltda, 1994

[6] HICKEY, M.W. Ultrafiltration specialty cheese workshop. The Australian Journal of Dairy Technology, n. 48, p. 40-48, 1993.

[7] HYDAMAKA, A.W.; WILBEY, R.A.; LEWIS, M.J.; KUO, A.W. Manufacture of heat and acid coagulated cheese from ultrafiltered milk retentates. Food Research International, n .34, p. 197-205, 2001.

[8] JAMESON, G.W. Manufacture of Cheddar cheese from milk concentrated by ultrafiltration: the development and evaluation of a process. Food Technology in Australia, n. 39, p. 560-564, 1987.

[9] JENSEN, G.K.; STAPELFELDT, H. Incorporation of whey proteins in cheese including the use of ultrafiltration. In: INTERNATIONAL DAIRY FEDERATION. Factors Affecting the Yield of Cheese. 1993, Brussels: International Dairy Federation Special Issue, n. 9301, chap. 9, p. 88-105.

[10] KINDSTEDT, P.S.; ZIELINSKI, A.; ALMENA-ALISTE, M. A post-manufacture method to evaluate the effect of pH on Mozzarella cheese characteristics. The Australian Journal of Dairy Technology, n. 56, p. 14-19, 2001

[11] MADSEN, J.S.; ARDO, Y. Exploratory study of proteolysis, rheology and sensory properties of Danbo cheese with different fat contents. International Dairy Journal, n. 11, p. 423-431, 2001.

[12] MCMAHON, D.J.; FIFE, R.L.; OBERG, C.J. Water partitioning in Mozzarella cheese and its relationship to cheese meltability. Journal of Dairy Science, n. 82, p. 1361-1369, 1999.

[13] PAHKALA, E.; TURUNEN, M.; ANTILA, V. Ultrafiltration in the manufacture of Edam cheese. Meijeritieteellinen Aikakauskirja, v. 43, p. 47-61, 1985. 
[14] RIBEIRO, E.P. Aplicação da Ultrafiltração de Leite no Processo de Fabricação de Queijo Tipo Prato. Campinas, 1996, 144 p. Dissertação (Doutorado em Tecnologia de Alimentos), Faculdade de Engenharia de Alimentos, Universidade Estadual de Campinas (UNICAMP).

[15] RENNER, E.; EL-SALAM, M.H.ABD. Application of Ultrafiltration in the Dairy Industry. London: Elsevier Applied Science, 1991.

[16] RICHARDSON, G.H. Standard Methods for Examination of Dairy Products. Washington: American Publ. Health Assoc., 1985.

[17] SOUZA, E.A. Tecnologia da Fabricação de Queijos. Juiz de Fora: Editora Lar Católico, 1960.

[18] STONE, H.; SIDEL, J.; OLIVER, R.S.; WOOLSEY, A.;
SINGLETON, RC. 1974. Sensory evaluation by quantitative descriptive analysis. Food Technology, n. 28, p. 24-34, 1974.

[19] VAN DENDER, A.G.F.; DUCRUET, P.; MAUBOIS, J.L. Estudo da fabricação de queijo tipo prato utilizando ultrafiltração. Revista do Instituto de Laticínios Cândido Tostes, n. 42, p. 7-14, 1987.

[20] ZOON, P. Incorporation of whey proteins into Dutchtype cheese. In: International Dairy Federation. Cheese Yield and Factors Affecting its Control. 1993, Cork: International Dairy Federation, p.403-408.

\section{6 - AGRADECIMENTOS}

Os autores agradecem à FAPESP (Auxílio à Pesquisa). e ao CNPq (bolsas de doutorado). 